\title{
Smartphone usage patterns in public universities in Malawi: student perspectives
}

\author{
Michael Francis Mwambakulu ${ }^{1}$ and Patrick Albert Chikumba ${ }^{2}$ \\ mwambakulu@gmail.com ORCID: 0000-0002-4348-7467 \\ pchikumba@poly.ac.mw ORCID: 0000-0002-7430-3720
}

\begin{abstract}
Received: 31 May 2020
\end{abstract}
Accepted: 30 October 2020

\begin{abstract}
This study was motivated by the shortage of qualitative studies on student uses and gratifications of smartphone technology. Most research studies on mobile device uses and gratifications are quantitative and focus on mobile phones. Further, these studies are quite general, with insufficient information on how participants in those studies appropriate and engage with the technology. The purpose of this study was to investigate motives for use and usage patterns of smartphones among public university students. The study employed qualitative methods in the form of face-to-face interviews, focus group discussions, questionnaires and document analysis. Uses and Gratifications Theory was employed as a theoretical framework to form the basis of this study as well as to interpret the findings. The study found that students were motivated to use smartphones for internet access, social media and communication. As for patterns of use, it was found that the pattern was dominated by social networking. This paper contributes to the body of knowledge by providing a rich understanding of smartphone uses and gratifications which has insufficiently been described in previous similar studies. The paper further added the concept of policy to the main categories of the uses and gratifications framework.
\end{abstract}

Keywords: Smartphone, smartphone usage patterns, smartphone usage policies, social media, Uses and Gratifications Theory

\section{Introduction}

The Malawi Growth and Development Strategy III (Ministry of Finance Economic Planning and Development 2017) specifies that, in order to improve the quality of higher education in Malawi, there is a need to improve usage of and access to Information and Communications Technologies (ICTs). Due to their increasing capabilities, such as computing power, increased storage capacity, Wi-Fi connectivity and upload capabilities, smartphones are popular ICT tools used in higher education institutions. Students in institutions of higher learning are leading in the usage of mobile devices (Al-Emran, Elsherif \& Shaalan 2016) using them while travelling, at home or at school. Previous studies on smartphone usage patterns among university students have resulted in two main schools of thought: firstly, that they are used for academic purposes and, secondly, that they are used for socialisation and communication. On one hand, students use smartphones for accessing and downloading academic resources from the internet in order to complete their coursework or assignments (Pullen et. al. 2015, Chaputula and Mutula 2018). On the other hand, students frequently use smartphones for chatting on social networking platforms, for phone calls and for text messaging (North, Johnston and Ophoff 2014, Echenique, Molías \& Bullen 2015, Shraim and Crompton 2015, Dania and Iwe-ewenode 2016, Thang et. al. 2016).

There is a shortage of qualitative studies on uses and gratifications of smartphone technology; most research studies are quantitative. Even though these studies are useful in indicating usage patterns, they are relatively general and do not focus on understanding the unique, in-depth, rich and individualistic lived experiences of study participants. These quantitative studies have been conducted in different countries (for example, Nigeria, Australia, Namibia, Malaysia, the United States of America and South Africa) and have produced different findings according to the context and culture in which they were conducted. Some researchers have questioned the accuracy of quantitative methods to study technology use among university students sufficiently (Bennett, Maton \& Kervin 2008, Selwyn 2008, Helsper and Eynon 2010). Hence, there is a call for further research incorporating qualitative data to provide more details on why and how students and young people engage with smartphones ( Bennett, Maton \& Kervin 2008, Selwyn 2008, Helsper and Eynon 2010, Paul et al. 2014, Shava, Chinyamurindi \& Somdyala 2016, Matto and Kazungu 2018). It is against this background that this study was carried out, using the case of public universities in Malawi. Some studies on mobile phone usage have been conducted in Malawi, yet none focused on motives for and patterns of use of smartphones among public university students. Therefore, the purpose of this study was to examine motives for use of smartphones and usage patterns of smartphones among

1. Michael Francis Mwambakulu is Systems Analyst at Malawi Universities Development Programme, Lilongwe, Malawi

2. Patrick Albert Chikumba is Lecturer at the Polytechnic, University of Malawi 
undergraduate students in public universities in Malawi when they are on campus. The following specific objectives guided the study:

- Establish factors that motivate university students to use smartphones in their everyday life.

- Explore behaviour related issues that students have as they use smartphones.

- Determine the presence of policies on use of mobile phones and the extent to which such policies shape patterns of smartphone usage.

\section{Related literature and conceptual framework}

This section is organised into factors influencing smartphone usage among university students, usage patterns of smartphones, policies on mobile phone usage in the classroom and the library, and a conceptual framework drawn from Uses and Gratifications Theory and the related literature.

\subsection{Factors influencing smartphone usage among university students}

In developing countries, several studies have been conducted on factors that influence smartphone usage among university students. Examples are from Bangladesh (Deb and Uddin 2018), Botswana (Lesitaokana 2015), Malaysia (Balakrishnan and Loo 2012), Malawi (Chaputula and Mutula 2018, Matto and Kazungu 2018), Nigeria (Dania and Iwe-ewenode 2016), South Africa (Shava, Chinyamurindi \& Somdyala 2016) and Saudi Arabia (Alfawareh and Jusoh 2014). Findings from these studies indicate various influencing factors which are summarised as follows.

- Internet connection: Students usually need to stay connected to the internet for various reasons, including accessing information, accessing online business services and for entertainment (Deb and Uddin 2018), accessing e-books and library websites (Chaputula and Mutula 2018), checking webpages, and downloading software (Alfawareh and Jusoh 2014). Students use their smartphones to connect to the internet due to, for example, dependability and affordability of mobile internet and inadequacy of computers at universities (Chaputula and Mutula 2018).

- Social interaction and communication: Smartphones enable students to expand their social network with the ability to connect with others easily and quickly regardless of physical location (Balakrishnan and Loo 2012). For example, they use smartphones for chatting on social networking platforms, especially Facebook and WhatsApp (Alfawareh and Jusoh 2014, Echenique, Molías \& Bullen 2015, Dania and Iwe-ewenode 2016, Shava, Chinyamurindi \& Somdyala 2016). Most students use smartphones for social support from their family and relatives, and for educational support from classmates and lecturers through Short Message Service (SMS), phone calls and Skype, for example (Gikas and Grant 2013, North, Johnston and Ophoff 2014, Lesitaokana 2015, Matto and Kazungu 2018).

\subsection{Smartphone usage patterns among university students}

Previous studies have shown different patterns of smartphone usage for social and academic purposes. Hossain (2019) found that the majority of respondents were accessing social networking sites such as Facebook during study time. Echenique, Molías \& Bullen (2015) found that most students were frequently using digital devices for socialisation and communication. The use of smartphone devices has been limited to social networking (Shraim and Crompton 2015). Besides voice calling and messaging, students use Facebook and WhatsApp for chatting purposes (Shava, Chinyamurindi \& Somdyala 2016). Dania and Iwe-ewenode (2016) also found that students spend much time chatting on social networks, especially Facebook. Nwachukwu and Onyenankeya (2017) indicated that calling friends and family is the most frequent activity students engage in on their smartphones, followed by social networking.

Makewa, Magaleta and Role (2017) found that students use smartphones to enhance their academic goals, especially by accessing educational materials and bilingual dictionaries. Hossain (2019) reported that many students access Google and other search engines, thereby turning their smartphones into research tools. These studies agree with the findings by Chaputula and Mutula (2018) and Dania and Iwe-ewenode (2016) who stated that most students have abandoned physical libraries as they now search for information on the internet through their smartphones. According to a study by Nnadozie, Ossai-onah and Anyanwu (2015) students use their smartphones to access online information resources in order to supplement classroom learning. As noted by Shava, Chinyamurindi \& Somdyala (2016), use of smartphones among students offers new educational opportunities and grows the desire to learn. One of these opportunities is mobile learning (m-learning), which enables learning through handheld or palmtop mobile technologies including mobile phones, smartphones, personal digital assistants and possibly also tablets and laptops, which allow anyone to access information and learning materials anywhere and at any time (Ally 2009). Researchers, such as Shraim and Cromton (2015) claim that mobile devices, with their many existing features and potential uses, are neither currently widely accepted nor utilised for learning in universities because, among others, they have been regarded as a distraction rather than a learning tool. If 
students use their smartphones in class, they are asked to put them away or turn them off (Shraim and Cromton 2015). The views that many features of these phones were designed for fun and that most students lack self-control in the absence of proper guidelines have not gone away.

\subsection{Policies on mobile phone usage in the classroom and library}

The presence of mobile technology devices in today's classrooms cannot be denied. University administrators face the dilemma of choosing between embracing these mobile technologies or limiting their use both in the classroom and the library. Several studies show that mobile technology legislation and policies are put in place to guide use of the technologies in general, including at school. Categories of mobile phone usage policies include prohibition and non-prohibition policies. Prohibition policies do not allow usage of mobile phones in classrooms, but no penalty is stated. Non-prohibition policies allow usage of mobile devices in the classroom but at the discretion of the lecturer. Often the policy would state that students can use their mobile phones in class or in the library as long as they do not disturb the learning environment. Studies by Ugur (2015) and Fernandez (2018) show that the majority of participants were aware of guidelines restricting usage of mobile phones during classes. Ugur (2015) reported that authorities were considering banning use of mobile phones in the classroom. Contrary to the findings of Ugur (2015), studies conducted by Fernandez (2018) and Chukwuere (2018) showed that students were against banning usage of mobile phones in classrooms as a majority of them used this tool for learning purposes. Matto and Kazungu (2018) however concluded that mobile phones should be prohibited in lecture rooms or switched off to prevent students chatting during lectures.

\subsection{Mobile phone usage and mobile learning}

M-learning is increasingly applied in many countries and brings opportunities to education systems for self-learning, collaboration, continuous and distant education, different learning styles and pace, mobility and interactivity (Hashim, Koo \& Song 2009, Klimova \& Poulova 2015). M-learning is a subset of electronic learning and supplements other learning methods. To access m-learning, students need mobile devices. In Malawi, mobile phone subscriptions are growing rapidly (Matto \& Kazungu 2018). For instance, by $2016,42.5 \%$ of the Malawian population owned mobile phones (Matita \& Chauma 2019). Nowadays, university students can study independently because they are equipped with smartphones (Klimova \& Poulova 2015). Increasingly, fourth generation (4G) connections lead to high ownership of smartphones among students in higher education (Handforth and Wilson 2019). Increasingly, university students can participate in m-learning because of mobile phone growth.

\subsection{Conceptual framework: Uses and Gratifications Theory (UGT)}

UGT has been one of the most common theories for measuring motivation to use technologies, ranging from radio and digital television to the internet and mobile phones. It focuses on why consumers use technology to satisfy their social and psychological needs. UGT emphasises three main objectives: to explain how individuals use technology to satisfy their needs; to discover motives behind individuals' use of technology; and to identify positive and negative consequences of individual technology use (Balakrishnan and Loo 2012). According to Balakrishnan and Raj (2012), the four concepts of UGT as they relate to mobile phones are:

- Reasons to use mobile phones: the need for socialisation, safety, privacy and status among others.

- Pattern of mobile phone usage: the average number of calls made and received daily among others.

- Behaviour issues: addiction, for example, using mobile phones in class, constantly checking the phone for messages, reading and replying to messages immediately, among others.

- Purchasing factors: related to price and brand of mobile phone, trends and usability.

UGT focuses heavily on self-reporting (Katz 1987). However, self-reports are based on personal memory which can be problematic (Nagel, Hudson and Abowd 2004). As such, the respondents might inaccurately recall how they behaved in relation to technology use and thus distortion might occur. Previous studies have demonstrated that UGT is useful for conceptualisation of mobile device technology usage. Table 1 provides an overview of some previous UGT studies. As illustrated in Figure 1, this research has been guided by the concepts drawn from the discussion on mobile phone uses and gratifications above.

- Motivating factors: This concept has been applied to understand the incentives that influence students to use smartphones.

- Pattern of smartphone usage: This concept has been adopted to understand how students use their smartphones when they are on campus. 
- Behavioural-related issues: This concept has been adopted to understand the positive and negative experiences that students have when they use smartphones.

- Policy issues: These have been applied to understand the presence of policies on use of mobile phones in universities and the extent to which such policies shape patterns of using smartphones.

Table 1: An overview of previous UGT studies

\begin{tabular}{|c|c|c|c|}
\hline Author & Research areas & Research methods & Identified key motivations \\
\hline Balakrishnan and Raj (2012) & Mobile phone & Quantitative & Socialisation and privacy \\
\hline Balakrishnan and Loo (2012) & Mobile phone and SMS & Quantitative & Socialisation and privacy \\
\hline Hoştut (2010) & Mobile phone & Quantitative & Sociability and relaxation \\
\hline North, Johnston and Ophoff (2014) & Mobile phone & Quantitative & Socialisation, safety and privacy \\
\hline lqbal (2010) & Mobile phone & Quantitative & Pleasure, affection and inclusion \\
\hline Whiting and Williams (2013) & Social media & Qualitative & $\begin{array}{l}\text { Social interaction, information seeking and } \\
\text { pastime }\end{array}$ \\
\hline Barashdi et al. (2015) & Smartphone & Qualitative & Information sharing and entertainment \\
\hline Quan-Haase and Young (2010) & Social media & Quantitative & $\begin{array}{l}\text { Pastime, affection, sharing problems, sociability } \\
\text { and social information }\end{array}$ \\
\hline Nelson (2015) & Social networking sites & Mixed & $\begin{array}{l}\text { Viewing and posting pictures, entertainment, } \\
\text { connecting with family and friends, and finding } \\
\text { creativity }\end{array}$ \\
\hline
\end{tabular}

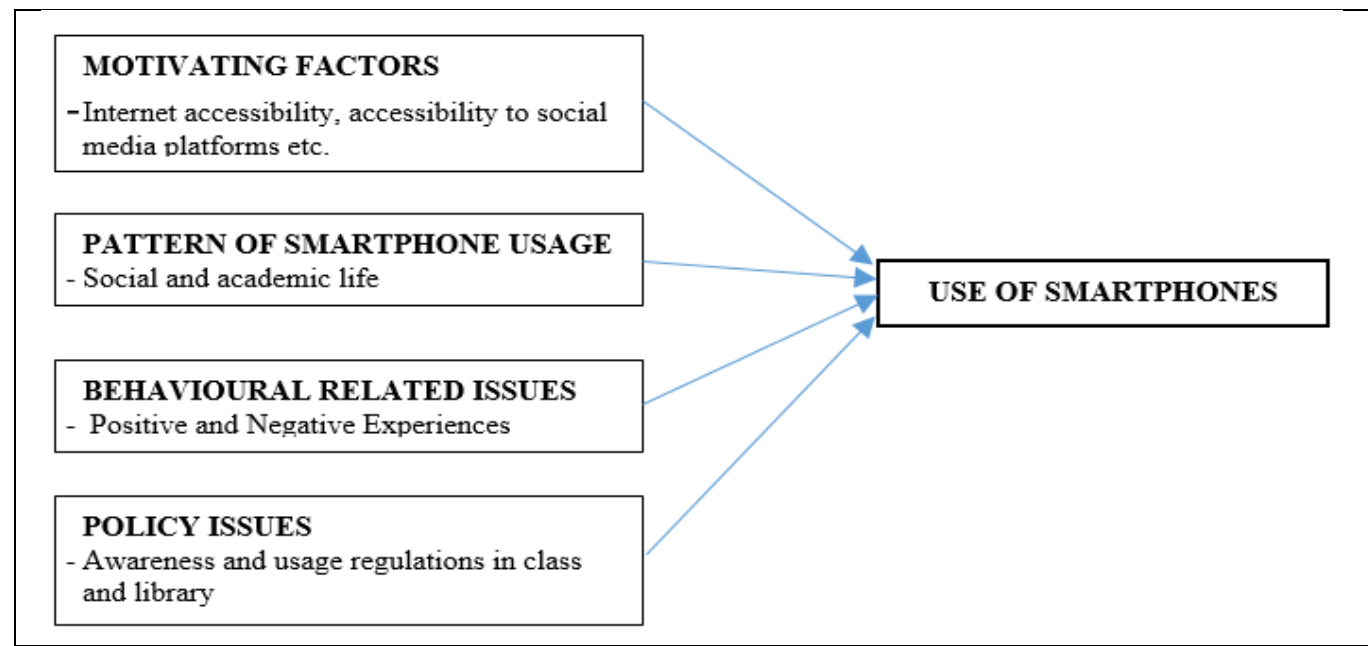

Figure 1: Conceptual framework for this study

\section{Research methodology}

This section presents the process that was followed to obtain research results; emphasis is on the significance of using qualitative methods and employing a case study approach. It also presents sampling and data collection methods and analysis techniques that were used in the study.

\subsection{Research approach}

This study adopted a qualitative approach because it is designed to help the researchers understand people and the social and cultural context within which they live (Myers 1997), that is, it provides a deeper understanding of the phenomenon under investigation (Yin 1994). The deductive approach to theory was employed in which data were collected based on the main themes defined in the conceptual framework based on UGT (see Figure 1). The case study took place in a university setting where researchers collected data in three public universities. In case studies, a researcher explores in-depth a program, event, activity, process or individuals. This strategy helped the researchers in gaining a rich understanding of smartphone usage among students in public universities in Malawi.

\subsection{Research setting}

The study was conducted in three public universities, namely the University of Malawi (UNIMA) (Kamuzu College of Nursing (KCN) and the Polytechnic), Lilongwe University of Agriculture and Natural Resources (LUANAR) (Bunda campus) and 
Malawi University of Science and Technology (MUST). These universities were considered appropriate for this study because the research focused on a public university setting. Each institution focuses on a specific niche such as agriculture and natural resources, nursing and midwifery, science and technology, or business and applied sciences. Each university enrolls students from different socioeconomic backgrounds across the country. Most students select public universities as their first choice for enrolment because these public universities are affordable and have better resources than most private universities.

\subsection{Population and sampling}

The research focused on undergraduate students drawn from the third and fourth years of study because the likelihood of them owning smartphones was high. It was also likely that, considering their experiences in academic activities, they would be smartphone users. Their characteristics cut across socioeconomic status. They had smartphones and had been using those smartphones for twelve months. They were either administrators of social networking groups or merely users. The study had a sample of 124 participants who were identified through purposive sampling. Creswell (2014) states that, in purposive sampling, the researcher selects individuals and sites for study purposefully because they can inform an understanding of the research problem and the central phenomenon of the study. It is essential that all participants have experience in the phenomenon being studied or that they represent people who have experienced the phenomenon. The primary concern of purposive sampling is to acquire in-depth information from those who can give it. In this study, purposive sampling was chosen because participants were those who could provide the information required because they were either able to articulate issues about or were once involved in usage of smartphones.

\subsection{Data collection}

Data was collected using in-depth interviews, focus group discussions, self-administered questionnaires and document analysis. The four methods were used to enrich data generated and to address limitations each instrument could present.

\subsubsection{In-depth interviews}

The researchers conducted fifty-four face-to-face interviews in different time periods (see Table 2). Each interview took approximately twenty minutes and researchers involved two facilitators to help in conducting the interviews because of time constraints during the data collection period (most respondents were busy with other commitments). Interviews offered researchers more detail and depth, allowing insight into how participants understand and narrate aspects of their lives (Bates et. al. 2008). It was possible to gain a deeper understanding of participants' experiences through dialogue and the language they use in their natural setting.

Table 2: In-depth interviews

\begin{tabular}{clcl}
\hline$\#$ & Study site & Interviews & Dates of interviews \\
\hline 1 & LUANAR - Bunda Campus & 21 & 14 and 18 December 2018 \\
2 & UNIMA - KCN & 15 & 7-8 December 2018 \\
3 & MUST & 18 & 10 December 2018 \& 25 January 2019 \\
\hline \multicolumn{2}{c}{ Total } & $\mathbf{5 4}$
\end{tabular}

\subsubsection{Focus group discussions}

Two focus group discussions were conducted, one at UNIMA - KCN and one at MUST, with a total of eighteen participants (see Table 3). Focus group discussions were not conducted at LUANAR and UNIMA - the Polytechnic due to procedural issues and bureaucracy. The focus groups gathered students to discuss issues on smartphone use at universities. As Wong (2008) pointed out, in a focus group, a small group of participants gathers to discuss a specified topic or an issue to generate data. A small group of six to ten participants (Morgan 2013) was considered appropriate, with the first author as the moderator.

Table 3: Focus group discussions

\begin{tabular}{clcl}
\hline$\#$ & Study site & Participants & Dates and times \\
\hline 1 & UNIMA - KCN & 10 & 8 December 2018, 50 minutes 17 seconds \\
2 & MUST & 8 & 25 January 2019, 58 minutes 2 seconds \\
\hline \multicolumn{2}{c}{ Total } & $\mathbf{1 8}$ & \\
\hline
\end{tabular}




\subsubsection{Questionnaires}

The face-to-face interviews and focus group discussions were complemented by self-administered questionnaires comprising both open-ended and closed questions which were used to collect data from fifty-two participants at the Polytechnic in July 2019. The questionnaires were used to collect data because the participants were not available for indepth interviews and focus group discussions due to other commitments.

\subsubsection{Document analysis}

Document analysis was done on national policy documents, strategies, plans and legislations (see Table 4) on the subject matter sourced from print and electronic media, official libraries and internet postings. The documents helped researchers track background and new developments in ICT in Malawi education. According to Creswell (2014), documents are important as they represent thoughtful data and save researcher's time and expenses that could have been incurred during the study. The authors decided to analyse specific documents based on their relevance to the research problem and purpose, and contents of documents according to the study conceptual framework.

Table 4 List of analysed documents

\begin{tabular}{|c|c|c|}
\hline \# & Document & Data extracted \\
\hline 1 & Malawi National ICT policy of 2013 & $\begin{array}{l}\text { Human capital development and related policy statement. } \\
\text { Universal access to ICT and related services }\end{array}$ \\
\hline 2 & Communications Act No. 34 of 2016 & Deployment and use of communication services \\
\hline 3 & National Education Sector Plan 2008-2017 & Higher education guiding principles \\
\hline 4 & $\begin{array}{l}\text { Malawi Growth and Development Strategy } \\
\text { (MGDS) III of } 2017\end{array}$ & Outcomes and strategies for higher education \\
\hline
\end{tabular}

\subsection{Data analysis}

The authors used content analysis to scrutinise data collected following the procedure recommended by Creswell (2014): data transcription, data coding, code categorisation, theme identification and grouping, and theme interpretation. Content analysis was suitable for this study because it helped researchers scrutinise the presence of certain words, themes or concepts within the data.

- Data transcription: The researchers transcribed data from interviews and focus group discussions into a written form, read and re-read the transcript in order to familiarise themselves with the data generated, and ensured that the transcript retained the required information from the verbal source and in a way that reflected the original source.

- Data coding: This involved reading the transcript line by line and applying codes to passages in the data.

- Code categorization: The different codes were sorted, then grouped into categories based on research objectives.

- Theme identification: Data was charted into the framework matrix and then a spreadsheet was used to summarise data by category from each transcript followed by an interpretation of the meaning of the themes.

- Theme grouping: Identified themes were sorted according to pre-defined themes based on the conceptual framework (influencing factors, usage pattern, behavioural-related issues and policy issues), which was followed by interpreting the meaning of the themes.

\section{Findings}

The research findings are presented in alignment with the concepts outlined in the conceptual framework (Figure 1).

\subsection{Motivating factors for using smartphones}

This study has identified three key motivating factors associated with smartphone usage: internet access, access to social media platforms, and communication. The results revealed that internet access was the most-cited motivating factor for smartphone use among public university students in Malawi.

\subsubsection{Internet access}

Specifically, the internet helps students to access academic and non-academic materials easily and at any time. It was established that availability of Wi-Fi and free internet access in all study sites had motivated students to use smartphones. Most students could not afford data bundles since access to the internet is very expensive for an average university student in Malawi. One participant said: 
Internet access is the main thing because most research is done on the internet, so we can't all be at the library. Computers are few, so some students use their phones.

Another participant commented:

We have free Wi-Fi which encourages students to use smartphones, even of low quality, as long as they are able to access information on the internet through the school Wi-Fi.

\subsubsection{Access to social media platforms}

Motives for using social media varied, from associating with friends, checking updates, and sending and receiving information to discussing group assignments on WhatsApp. In one focus group discussion, some participants commented as follows:

- WhatsApp has the capability of sending files in different formats like PDF. We share slides through the WhatsApp class group and that is why WhatsApp is commonly used. For school to be easy, you need to have a smartphone.

- I use my smartphone to access breaking news on WhatsApp.

- WhatsApp makes interaction between peers easier; you can send a lot of things.

\subsubsection{Communication}

A third important factor that emerged from the data concerning motivating factors for use of smartphones among students was communication. The specific examples mentioned by respondents were using them for access to student information systems, phone calls, SMS and school emails among others. The study discovered that smartphones facilitate communication among students within and outside the university campus; beyond providing a communication platform, smartphones facilitate academic group discussions through social media platforms like WhatsApp. Respondents further observed that, in cases of academic problems, where answers are hard to provide, they just take a picture of a written solution. As one participant narrated:

There are mathematical questions which are hard to provide an answer on a WhatsApp group, unless you take a picture of a solution which you have solved on a separate paper and send it to the group. Or maybe your fellow student is at home and you have learnt something, you can send him or her a screenshot. If he or she needs an explanation, you can just record an audio and send it through WhatsApp.

\subsection{Smartphone usage patterns}

There was a disparity among participants about smartphone usage patterns in specific time periods (see Table 5). However, overall, the study has identified social networking (with the total frequency of 385) as the most common usage of smartphones. The second common usage was for studying (with the total frequency of 325), followed by searching for information on the internet (with the total frequency of 288).

Table 5: Top three smartphone usage patterns per time periods

\begin{tabular}{lcl}
\hline Time periods & Frequency $^{*}$ & Smartphones are used \\
\hline \multirow{2}{*}{$05 \mathrm{~h} 00-07 \mathrm{~h} 30$} & 88 & for communication \\
& 86 & for social networking \\
& 58 & for studying \\
\hline \multirow{2}{*}{$07 \mathrm{~h} 30-12 \mathrm{~h} 00$} & 78 & for social networking \\
& 60 & for studying \\
& 48 & to search information on the internet \\
\hline \multirow{3}{*}{$12 \mathrm{~h} 00-14 \mathrm{~h} 00$} & 70 & for entertainment \\
& 65 & for social networking \\
& 56 & to search information on the internet \\
\hline \multirow{3}{*}{ Beyond $14 \mathrm{~h} 00$} & 207 & for studying \\
& 184 & to search information on the internet \\
& 156 & for social networking \\
\hline
\end{tabular}

${ }^{*}$ Frequency does not sum to 124 because of multiple responses sourced from data analysis coding books 
Early in the morning, the majority of respondents used smartphones to communicate with peers, lecturers and relatives via phone calls, SMS, emails and social networking platforms. One participant commented: I use a smartphone to know about the welfare of my relatives. Besides communication, the majority of students use their smartphones for social networking, particularly using WhatsApp. Several participants indicated that, during the course of the morning, they use smartphones for studying, particularly for storing e-books, reading electronic materials, and accessing and downloading academic materials from the internet. Findings have indicated that most students go into classes and the library with smartphones which they mostly use for WhatsApp chatting, sharing information and checking class updates. Many participants mentioned that they use smartphones to, for example, take screen shots of notes, access dictionaries, conduct academic research on the internet and read lecture notes. One participant emphasised:

At the end of each class, lecturers give us soft copy notes, so we use our phones to store and read those notes.

However, in some situations, students use smartphones with bad intentions as another participant said:

We sometimes chat with friends on WhatsApp or Facebook when the class is boring ... but we make sure that the lecturer should not notice what we are doing.

When they are breaking for lunch, participants usually use smartphones for entertainment and social networking. The audio-visual features on smartphones were mentioned by most participants to be useful for listening to music, watching videos and taking pictures. One participant said:

Not all students use smartphones for searching information on the internet. Others use these phones to listen to music and watch videos ... This time is used as part of refreshment by listening to music as we are on lunch time.

In the afternoon, participants usually use their smartphones for studying and information seeking on the internet. It was observed that some students use smartphones for studying in the library, slowly, yet seriously replacing hard copies of textbooks. One participant said:

When I am free, I use my smartphone to study in the library and do other issues related to academic stuff.

Another participant corroborated:

Let's say you have been given an assignment, the only free time you can do that assignment is from $3 \mathrm{pm}$. We go to specific places where Wi-Fi is accessible to download the required information.

Late in the afternoon, when students have just come out of classes, they opt to use the college Wi-Fi for different purposes.

\subsection{Behavioural-related issues}

The third extracted theme was about behaviour related to the use of smartphones. Participants were observed on both positive and negative impacts of smartphone usage (see Table 6). Participants had a common perception that smartphones help in communication and they make academic life easy, citing, among others, easy access to academic materials on the internet and the ability to conduct group discussions on WhatsApp. The invention of the smartphone has eased costs for accessing information like academic results. They also noted that smartphones motivate students to go further with their education as it lessens the burden of looking for textbooks which are mostly scarce and expensive in Malawi. However, the findings indicate that many participants were concerned about the negative impact of using smartphones, particularly loss of concentration during learning, access to pornographic materials and promotion of risky behaviour especially to female students in search of money to buy voice and data bundles. The issue of addiction to social media was also observed. It was seen to have negative effects on learning among the victims, as one participant said:

When my smartphone is switched off, I don't feel good. I am addicted to checking messages from my boyfriend ... Some lecturers make class unexciting so, instead, I check messages on WhatsApp. 
While another participant commented:

I fail to concentrate during classes when my smartphone is switched on; I am tempted to check messages.

Table 6: Positive and negative experiences of using smartphones

\begin{tabular}{ll}
\hline Positive experiences & Negative experiences \\
\hline Helps to find information on the internet & Loss of concentration for learning \\
Easy communication & Expensive to buy airtime and data bundles \\
Entertainment & Addiction \\
Makes school or life easy & Erratic internet connection \\
Easy access to information & Short battery life \\
Access to social networking platforms & Access to pornographic materials \\
Helps to get class updates and conduct group discussions on & Limits physical interaction \\
WhatsApp & Prone to misuse \\
Helps in studying / reading notes & Promotes immoral behaviour \\
Easy to share files and e-books & Limited storage capacity \\
Less expensive or cheap to use & Tool for spreading fake news on social media \\
Helps to store soft copy materials & Leakage of sensitive information \\
Portability & Low self-esteem \\
Helps in online student registration & Sharing of private conversations \\
& Small screen size \\
\hline
\end{tabular}

\subsection{Policy issues on usage of mobile phones}

The fourth extracted theme was policy issues on usage of smartphones in terms of awareness and regulation of mobile phone usage in the classroom.

\subsubsection{Awareness of university policy on usage of mobile phones}

Participants unanimously agreed on the existence of university policies regarding use of mobile phones during classes or when studying in the library but differed on policy compliance in classrooms when learning is in session. Some said they comply with the policy while others said they do not. For example, one student said that the university does not allow use of smartphones in class, although this policy is mostly flouted by students.

The policy is there, but we use our smartphones when recommended. Sometimes lecturers tell us to search for some information on the internet in groups so, in those cases, we use our smartphones, but when the lecture is in session, it is prohibited to use the phone.

In the library, students are required to put their smartphones in silent mode.

\subsubsection{Regulation of mobile phone usage}

Significantly, participants agreed that use of smartphones during classes or when studying in the library needed to be regulated with reasons including smartphones resulting in less concentration on studies among those addicted to them, and disturbances caused by peers. One participant stated:

In class, most students don't concentrate, so I think it is necessary to regulate use of mobile phones.

This statement was corroborated by another participant who said: When the phone rings, I lose attention. It was noted that some students wear headsets, listening to music during lectures and others are addicted to social media and thus distracted during class time. Some participants disagreed about regulation. They argued that restricting use of smartphones is tantamount to a violation of the right to information. They stressed that usage regulation is not necessary because smartphones help them in the search for information on the internet. They said that the university is an adult learning environment with every student being responsible for his or her academic work.

\section{Discussion}

This study found the motives for using smartphones by public university students in Malawi to be accessing the internet, engaging with social media, and communicating. The findings are in line with those from various studies (Balakrishnan and Raj 2012, North, Johnston and Ophoff 2014, Echenique, Molías \& Bullen 2015, Shava, Chinyamurindi \& Somdyala 2016) on uses and gratifications of smartphones by university students in developing countries. As noted by Nwachukwu and Onyenankeya (2017), the majority of students spend a lot of time interacting on social media platforms. Findings of this 
study indicate that, among the social networking platforms, most participants interact on WhatsApp. In the Malawian context, the WhatsApp service is cheaper than alternative social media platforms like Facebook. Findings show that usage patterns of smartphones by university students differ according to time of day. However, the common smartphone usage pattern is the use of social networking mainly for sharing class updates and chatting on WhatsApp. Previous studies of Balakrishnan and Loo (2012) and North, Johnston and Ophoff (2014) found that text messaging dominated usage patterns. This paper argues that it was so because, at that time, WhatsApp was not as mature and popular as it is today. Further, it was observed in this study that usage of smartphones for social networking also fits well into students' learning, for example, most students use WhatsApp groups to discuss academic work and share learning materials. This observation is contrary to findings of other researchers (Dania and Iwe-ewenode 2016, Shava, Chinyamurindi \& Somdyala 2016, Hossain 2019) who observed that most students use social networking platforms for chatting purposes. The issue of students accessing social media platforms when a lecture is in session is not a new one. Ugur (2015), Olufadi (2015) and Hossain (2019) had similar findings in their studies. The implication is that students spend a considerable amount of time on their smartphones networking with friends and not necessarily for academic purposes. Fernandez (2018) stated that students do not use mobile phones in the classroom when they get bored with the lecture. This contradiction can exist due to differences in contexts of study.

The main reason that students use smartphones for academic purposes is that most public universities in Malawi have an inadequate number of computers for their students and lack the latest and most relevant textbooks in their libraries. Other studies (Dania and Iwe-ewenode 2016, Chaputula and Mutula 2018, Hossain 2019) had similar findings. This paper argues that most students have abandoned physical libraries as they now search for information on the internet using their smartphones. This is possible because of Wi-Fi coverage across university campuses and the cost reduction of internet connectivity. The Malawi National Education Sector Plan is promoting increased access to the internet across university campuses (Ministry of Finance Economic Planning and Development 2017). In this study, students' behavioural-related issues were found to influence use of smartphones: there was an overwhelming concern about negative effects of smartphones as shown in Table 6. The findings are consistent with results of Balakrishnan and Raj (2012), North, Johnston and Ophoff (2014) and Singh and Samah (2018). The concern about loss of concentration during learning was more common than concern about addiction and access to pornographic materials. University students spend much time on their smartphones networking and chatting with their peers or in search of entertainment. Nevertheless, there was a strong view that smartphones are effective mechanisms for providing education in collaboration with traditional methods, concurring with what Dania and Iwe-ewenode (2016) observed.

The study recommends introducing and promoting m-learning in public universities by, for example, developing a platform where students can interact with their lecturers online, and introducing facilities like lecture videos by local lecturers as alternatives to YouTube downloads, which in some instances are expensive to access. The use of smartphones in a classroom should be regulated, otherwise the role of lecturer will continue not to be fully utilised. Students should use smartphones as supplements to, rather than replacements for, classroom learning. As some participants observed, the usage of smartphones during classes or when studying in the library should be regulated in order to avoid misuse and disturbances which is consistent with the findings of Matto and Kazungu (2018). Although Fernandez (2018) found that students were against regulating use of mobile phones in classrooms as a majority of them used this tool for learning purposes, in Malawian public universities it is necessary to regulate use of smartphones and other mobile devices in the classroom when, and only when, they are advised by their lecturers.

\section{Contributions, limitations and conclusion}

This study enhances the work of quantitative studies of Hoştut (2010), Balakrishnan and Raj (2012), North, Johnston and Ophoff (2014) and Nelson (2015) on uses and gratifications of mobile phone technology. That is, the study has bridged the gap of scarcity of qualitative studies by collecting data on lived experiences and gaining an in-depth understanding of motives for use and usage patterns of smartphones among university students. This paper argues that, apart from indicating the general uses and gratifications of technology, studies on how and why university students appropriate and engage with technology are important. Adoption and use of technology are very much culture and context dependent. From the main categories of UGT (Balakrishnan and Raj 2012), this paper has added the concept of policy to understand the presence of mobile phone policies and the extent to which such policies shape the pattern of using smartphones. Below, are some limitations of this study.

- The sample population involved only university students who were enrolled in face-to-face programmes. In Malawi public universities, some programmes are also delivered through open distance and blended learning methods in which smartphones are in great use. 
- This study involved only students among several stakeholders such as lecturers, administrators, support staff and technologists. To enhance the understanding of m-learning qualitatively, it is important to include these other stakeholders.

It has been observed that use of smartphones in learning activities is here to stay. The paper recommends, as other studies have done, that Malawian universities should utilise the opportunity of m-learning, particularly to supplement classroom learning aimed at advancing sustainable and inclusive education. However, there is a need to regulate the use of smartphones in the classroom. This should involve the participation of college administrators, lecturers, and students as the key stakeholders of m-learning. Promoting m-learning, expanding Wi-Fi coverage across the university campus, and making internet rates more affordable would go a long way to encouraging more students, especially the poor, to use smartphone technologies.

\section{References}

Al-Emran, M., Elsherif, H. and Shaalan, K. 2016. Investigating attitudes towards the use of mobile learning in higher education. Computers in Human Behavior, 56: 93-102.

Alfawareh, H.M. and Jusoh, S. 2014. Smartphones usage among university students: Nayran University case. International Journal of Academic Research, 6(2): 321-326.

Ally, M. 2009. Mobile learning: transforming the delivery of education and training. Edmonton: AU Press.

Balakrishnan, V. and Loo, H. 2012. Mobile phone and short message service, appropriation, usage and behavioral issues among university students. Journal of Social Sciences, 8(3): 364-371.

Balakrishnan, V. and Raj, R.G. 2012. Exploring the relationship between urbanized Malaysian youth and their mobile phones: a quantitative approach. Telematics and Informatics, 29(3): 263-272.

Barashdi, H., Bouazza, A., Jabur, N.H. and Zubaidi, A. 2015. Smartphone gratifications among Sultan Qaboos university undergraduates: a mixed approach investigation. British Journal of Education, Society \& Behavioural Science, 10(1): $1-17$.

Bates, E., Droste C, Cuba, L. and Swingle, J. 2008. One-On-One Interviews: A Qualitative Assessment Approach. [Online]. https://docplayer.net/8672054-One-on-one-interviews-a-qualitative-assessment-approach.html (29 March 2018).

Bennett, S., Maton, K. and Kervin, L. 2008. The 'digital natives' debate: a critical review of the evidence. British Journal of Educational Technology, 39(5): 775-786. DOI:10.1111/j.1467-8535.2007.00793.x.

Chaputula, A.H. and Mutula, S. 2018. Factors impacting library-related uses of mobile phones by students in public universities in Malawi. South African Journal of Libraries and Information Science, 84(1): 35-46.

Chukwuere, J. 2018. The effect of smartphones on students' academic life: A perceptive from a South African University. Paper presented at the International Conference on Business and Management Dynamics. 29-31 August. Cape Town, South Africa.

Creswell, J.W. 2014. Research design : qualitative, quantitative, and mixed methods approaches. $4^{\text {th }}$ ed. Los Angeles, CA.: Sage.

Dania, P.O. and Iwe-ewenode, J. 2016. Undergraduate usage of mobile phones and its implication of school application. Journal of Education and Practice, 7(21): 30-32.

Deb, S.K. and Uddin, K. 2018. Empirical analysis of factors affecting the adoption of smartphone on young generation. International Journal of Management Science and Business Administration, 4(2), 17-24.

Echenique, E.G., Molías, L.M. and Bullen, M. 2015. Students in higher educatio: social and academic uses of digital technology. International Journal of Educational Technology in Higher Education, 12(1): 25-37.

Fernandez, S. 2018. University student's perspectives on using cell phones in classrooms: are they dialling up disaster? The Turkish Online Journal of Educational Technology, 17(1): 246-258.

Gikas, J. and Grant, M. 2013. Mobile computing devices in higher education: students' perspectives on learning with cellphones, smartphones and social media. The Internet and Higher Education, 19: 18-26.

Handforth, C. and Wilson, M. 2019. Digital Identity Country Report: Malawi. s.I.: GSM Association.

Hashim, H., Koo, C. and Song, H. 2009. Exploring learner's perception of mobile learning. Paper presented at the International conference on E-learning. 17-20 June 2009. Algarve, Portugal.

Helsper, E. and Eynon, R. 2010. Digital natives: where is the evidence? British Educational Research Journal, 36(3): 503-520.

Hossain, M. 2019. Impact of mobile phone usage on academic performance. An International Scientific Journal, 118(2019): 164-180.

Hoştut, S. 2010. Uses and gratification of mobile phone usage among students in Turkey. Global Media Journal: Mediterranean Edition, 5(1/2): 10-17.

lqbal, Z. 2010. Gender differences in mobile phone use: what communication gratifications does it gratify? European Journal of Scientific Research, 46(4): 510-522.

Katz, E. 1987. Communication research since Lazarsfeld. Public Opinion Quarterly, 51: 525-545.

Klimova, B. and Poulova, P. 2015. Mobile learning in higher education. Advanced Science Letters, 22(5-6): 1111-1114. DOI:10.1166/asl.2016.6673. 
Lesitaokana, W. 2015. Influencing factors to mobile phone adoption among urban youth in Botswana. Journal of Media and Communication Studies, 8(1): 8-14.

Makewa, L.N., Magaleta, I. and Role, J. 2017. Prevalence of mobile phone use in academic and social life of students and educators. Journal of Scientific Research and Studies, 4(1): 1-12.

Matita, M.M. and Chauma, T. 2019. Does financial literacy influence use of mobile financial services in Malawi? Evidence from Malawi household survey data. Nairobi: African Economic Research Consortium (AERC).

Matto, G. and Kazungu, I. 2018. Mobile phone and chat apps usage among Malawi university students. Research Report Series (RRS), 2(1): 73-85.

Ministry of Finance Economic Planning and Development. 2017. The Malawi growth and development strategy (MGDS) III (2017-2022): building a productive, competitive and resilient nation. Lilongwe: Government Press. [Online]. https://www.undp.org/content/dam/malawi/docs/UNDP_Malawi_MGDS)\%20III.pdf. (21 June 2018).

Morgan, D. L. 2013. Focus groups as qualitative research: planning and research design for focus groups. Thousand Oaks, CA: Sage.

Myers, M. D. 1997. Qualitative research in Information Systems. MIS Quarterly, 21(2).

Nagel, K.S., Hudson, J.M. and Abowd, G.D. 2004. Predictors of availability in home life context-mediated communication. Proceedings of the 2004 ACM conference on Computer supported cooperative work. 6-10 November. Chicago, IL.: ACM.

Nelson, D. 2015. Millennial social networking behaviour from uses and gratifications perspective. PhD thesis. NC State University.

Nnadozie, C. O., Ossai-onah, O.V. and Anyanwu, A.J. 2015. Use of smartphone amongst final year students' in School of Industrial and Applied Science (SIAS) In Federal Polytechnic Nekede-Owerri, Imo State, Nigeria. International Journal of Computer \& Organisation Trends, 16(1): 1-5.

North, D., Johnston, K. and Ophoff, J. 2014. The use of mobile phones by South African university students. Issues in Information Science and Information Technology, 11: 115-138.

Nwachukwu, C. and Onyenankeya, K. 2017. Use of smartphones among college students in Nigeria: revelations and reflections. Journal of Communication, 8(2): 171-182.

Olufadi, Y. 2015. Gravitating towards mobile phone during lecture periods by students: why are they using it? and how can it be measured? Computers \& Education, 87: 423-436.

Paul, B., Roy, S., Saha, I., Misra, R., Chattopadhyay, S. and Sasu, M. 2014. Mobile phone usage pattern among undergraduate medical students at a Medical College of Kolkata, West Bengal, India. Turkish Journal of Public Health, 12(3): 178-187.

Pullen, D., Swabey, K., Abadooz, M., and Sing, T. 2015. Pre-service teachers' acceptance and use of mobile learning in Malaysia. Australian Educational Computing, 30(1): 1-14.

Quan-Haase, A. and Young, A. 2010. Uses and gratifications of social media: a comparison of Facebook and instant messaging. Bulletin of Science Technology \& Society, 30(35). DOI:10.1177/0270467610380009.

Selwyn, N. 2008. An investigation of differences in undergraduate academic use of internet. Active Learning in Higher Education, 9(1): 11-12.

Shava, H., Chinyamurindi, W. and Somdyala, A. 2016. An investigation into the usage of mobile phones among technical and vocational educational and training students in South Africa. South African Journal of Information Management, 18(1): 1-8.

Shraim, K. and Crompton, H. 2015. Perceptions of using smart mobile devices in higher education teaching: A case study from Palestine. Contemporary Educational Technology, 6(4): 301-318.

Singh, M.K.K. and Samah, N.A. 2018. Impact of smartphone: a review of positive and negative effects on students. Asian Social Science, 14(11): 83-89.

Thang, S.M., Wah Lee, K., Murugaiah, P., Mohd Jaafar, N., Keong Tan, C. and Ahmad Bukhari, N. 2016. ICT tools pattern of use among Malaysian ESL undegraduates. Journal of Language Studies, 16(1): 49-65.

Ugur, N. G. 2015. Mobile phones as distrating tools in the classroom: College students' perspective. The Journal of Operations Research, Statistics, Econometrics and Management Information Systems, 3(2): 57-64.

Whiting, A. and Williams, D. 2013. Why people use social media: a uses and gratifications approach. Qualitative Market Research, 16(4): 362-369

Wong, L.P. 2008 Focus group discussion: a tool for health and medical research. Singapore Medical Journal, 49(3): 256261.

Yin, R. K. 1994. Case study research: design and methods. $2^{\text {nd }}$ ed. Thousand Oaks: SAGE. 